Research Article

\title{
Use of mNUTRIC-Score for Nutrition Risk Assessment and Prognosis Prediction in Critically Ill Patients with COVID-19: A Retrospective Observational Study
}

\author{
Francisco G. Yanowsky-Escatell ${ }^{\mathbb{D}},{ }^{1,2,3}$ Areli L. Ontiveros-Galindo, ${ }^{1}$ \\ Kevin J. Arellano-Arteaga, ${ }^{1}$ Luis M. Román-Pintos, ${ }^{1,3}$ Carlos A. Andrade-Castellanos, \\ Diana M. Hernández-Corona, ${ }^{4}$ Tonatiuh González-Heredia, ${ }^{4}$ \\ and Geannyne Villegas-Rivera ${ }^{3}$ \\ ${ }^{1}$ Departamento de Medicina Interna, Hospital Civil de Guadalajara Dr. Juan I. Menchaca, Guadalajara, Jalisco, Mexico \\ ${ }^{2}$ Programa de Doctorado en Investigación Multidisciplinaria en Salud, Centro Universitario de Tonalá, \\ Universidad de Guadalajara, Guadalajara, Jalisco, Mexico \\ ${ }^{3}$ Departamento de Ciencias de la Salud-Enfermedad como Proceso Individual, Centro Universitario de Tonalá, \\ Universidad de Guadalajara, Guadalajara, Jalisco, Mexico \\ ${ }^{4}$ Departamento de Ciencias Biomédicas, Centro Universitario de Tonalá, Universidad de Guadalajara, Guadalajara, \\ Jalisco, Mexico \\ Correspondence should be addressed to Francisco G. Yanowsky-Escatell; fyanowsky@hotmail.com
}

Received 14 August 2021; Revised 5 November 2021; Accepted 8 December 2021; Published 22 December 2021

Academic Editor: Mohammad-Salar Hosseini

Copyright (c) 2021 Francisco G. Yanowsky-Escatell et al. This is an open access article distributed under the Creative Commons Attribution License, which permits unrestricted use, distribution, and reproduction in any medium, provided the original work is properly cited.

\begin{abstract}
Introduction. Nutritional risk is highly prevalent in patients with COVID-19. Relevant data on nutritional assessment in the critically ill population are scarce. This study was conducted to evaluate the modified Nutrition Risk in the Critically Ill (mNUTRIC)-Score as a mortality risk factor in mechanically ventilated patients with COVID-19. Methods. We conducted this retrospective observational study in critically ill patients with COVID-19. Patients' characteristics and clinical information were obtained from electronic medical records. The nutritional risk for each patient was assessed at the time of mechanical ventilation using the mNUTRIC-Score. The major outcome was 28-day mortality. Results. Ninety-eight patients were analyzed (mean age, $57.22 \pm 13.66$ years, $68.4 \%$ male); $46.9 \%$ of critically ill COVID-19 patients were categorized as being at high nutrition risk (mNUTRIC-Score of $\geq 5$ ). A multivariate logistic regression model indicated that high nutritional risk has higher 28-day hospital mortality $(\mathrm{OR}=4.206,95 \% \mathrm{CI}$ : $1.147-15.425, p=0.030)$. A multivariate Cox regression analysis showed that high-risk mNUTRIC-Score had a significantly increased full-length mortality risk during hospitalization $(\mathrm{OR}=1.991,95 \% \mathrm{CI}: 1.219-3.252, p=0.006)$. Conclusion. The mNUTRIC-Score is an independent mortality risk factor during hospitalization in critically ill COVID-19 patients.
\end{abstract}

\section{Introduction}

The severe acute respiratory syndrome coronavirus 2 (SARSCoV-2), the causative agent of coronavirus disease 2019 (COVID-19), has attacked Latin American countries with varying intensity. Mexico in particular has some of the highest number of confirmed cases and COVID-related deaths in the world [1].
As COVID-19 cases and deaths continue to increase in our region, the role of nutritional assessment in these patients is gradually gaining momentum [2-5]. Malnutrition and risk of malnutrition has been associated with increased mortality and poor long-term outcomes in certain populations $[6,7]$. This is particularly true in patients with pneumonia in which impaired muscle and respiratory function is invariably present [8]. 


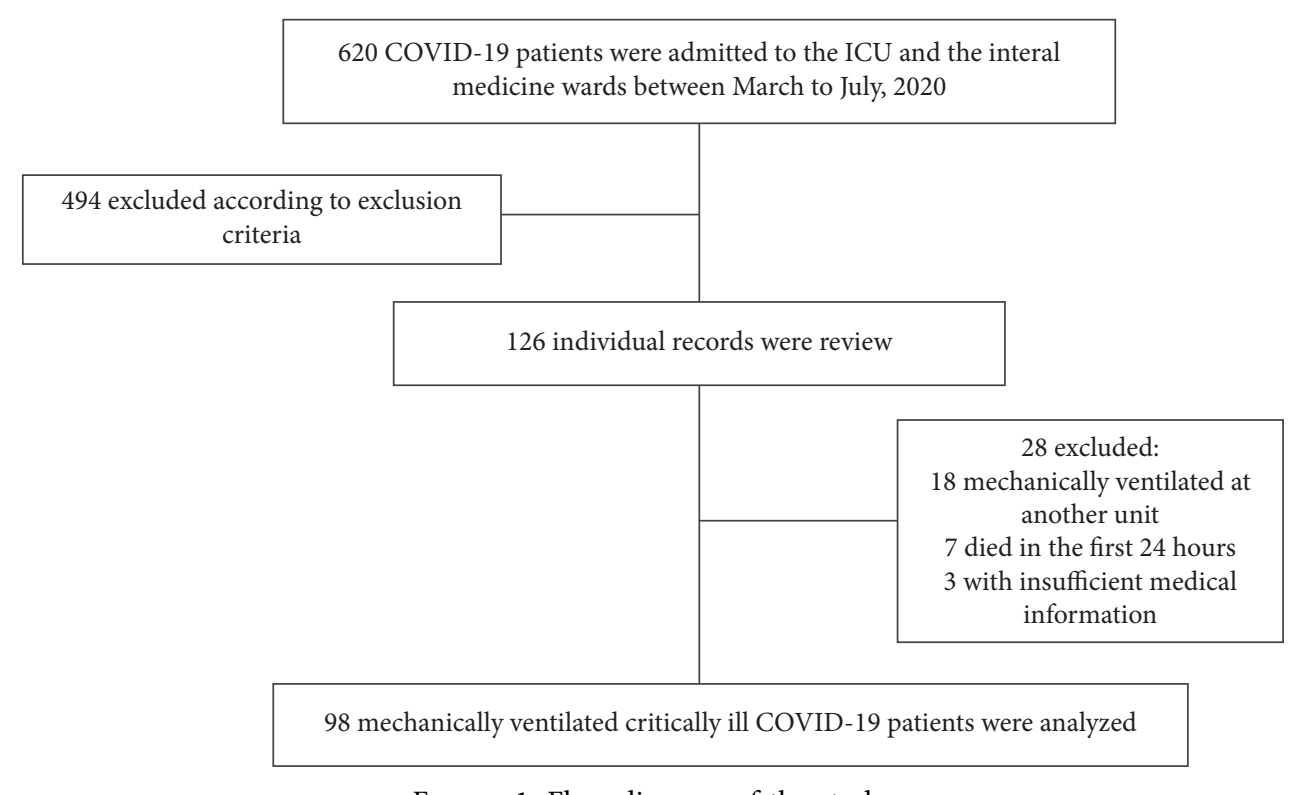

FIGURE 1: Flow diagram of the study.

SARS-CoV-2 infection is associated with a catabolic state and anabolic resistance leading to increased nutritional demand. Dietary intake reduction in COVID-19 population is fairly common. Studies have described anorexia, dysgeusia, and anosmia as important factors leading to fasting and weight loss [9]. Therefore, the identification of the risk and presence of malnutrition is considered an integral part of the approach to patients with COVID-19 in general healthcare [10].

The Nutrition Risk in the Critically Ill (NUTRIC)-Score is calculated retrospectively including age, routinely severity scores, comorbidity numbers, and pre-ICU hospital length of stay to identify patients who will benefit from early nutrition therapy $[11,12]$. In its original version, interleukin-6 (IL-6) was used as an inflammatory marker associated with nutritional risk. However, due to the difficulty of obtaining this measurement in regular clinical practice, the score was later validated without the use of IL-6 [12-14]. The adjusted score was called the modified NUTRIC (mNUTRIC)-Score. During the COVID-19 pandemic, an increased prevalence of high nutritional risk has been reported in other studies of critically ill patients using the mNUTRICScore [15-17].

The aim of the present study was to evaluate mNUTRICScore as a mortality risk factor in mechanically ventilated patients with COVID-19 and, also, to analyze nutritional risk and clinical outcomes in mechanically ventilated patients with COVID-19 in a tertiary care hospital in Mexico.

\section{Patients and Methods}

This is a retrospective observational cohort study conducted at the Hospital Civil de Guadalajara Dr. Juan I. Menchaca, a tertiary care hospital in Jalisco, Mexico. All patients admitted to the adult ICU and the internal medicine wards diagnosed with COVID-19, defined by a positive reversetranscriptase-polymerase-chain-reaction (RT-PCR) test for
SARS-CoV-2 by nasopharyngeal swab, from March to July 2020, and for whom the necessary information was available, were included in the study. Patients under the age of 18 years, pregnant patients, patient requiring surgical intervention, and patients not requiring mechanical ventilation were excluded from the study. The final cohort included 98 individual records (Figure 1), and the project was approved by the Institutional Review Board under research protocol no. $04553 / 20$, HCJIM/2021, and permitted by our hospital Ethics Committee.

2.1. Clinical Variables and Data Collection. We reviewed data related to demographics, clinical characteristics, and comorbidities (diabetes, hypertension, coronary heart disease, chronic kidney disease, and chronic obstructive pulmonary disease) from electronic health records through a standardized form. We collected the following variables: hospital length of stay, length of mechanical ventilation, and 28-day mortality. The partial pressure of arterial oxygen to the fraction of inspired oxygen $\left(\mathrm{PaO}_{2} / \mathrm{FiO}_{2}\right)$ ratio, Sequential Organ Failure Assessment (SOFA) score, the Acute Physiology and Chronic Health Evaluation II (APACHE II), and laboratory values that included glucose, creatinine, blood urea nitrogen (BUN), albumin, inflammatory markers (Creactive protein), electrolytes, and acid-base status were collected at the time of mechanical ventilation. The nutritional risk for each patient was assessed on the day of mechanical ventilation initiation using the mNUTRIC-Score ( 0 to 9 points). This score was calculated based on the NUTRIC-Score by eliminating IL- 6 values. A score of $\geq 5$ indicated a high nutritional risk $[12,13]$. Patients who received nutrition therapy within $48 \mathrm{~h}$ after the initiation of mechanical ventilation were considered early feeding cases according to the European Society for Clinical Nutrition and Metabolism (ESPEN) guidelines and $>48 \mathrm{~h}$ were considered late feeding [18]. 
TABLE 1: Characteristics of mechanically ventilated critically ill COVID-19 patients.

\begin{tabular}{|c|c|}
\hline & $n=98$ \\
\hline Age, years & $57.22 \pm 13.66$ \\
\hline Male, $n(\%)$ & $67(68.4 \%)$ \\
\hline Comorbidities & $1(0-7)$ \\
\hline Diabetes, $n(\%)$ & $35(35.7 \%)$ \\
\hline Hypertension, $n(\%)$ & $44(44.9 \%)$ \\
\hline Coronary heart disease, $n(\%)$ & $17(17.3 \%)$ \\
\hline Chronic kidney disease, $n(\%)$ & $8(8.2 \%)$ \\
\hline Chronic obstructive pulmonary disease, $n(\%)$ & $4(4.1 \%)$ \\
\hline Charlson comorbidity index & $2(0-9)$ \\
\hline \multicolumn{2}{|l|}{ Severity of disease } \\
\hline $\mathrm{PaO}_{2} / \mathrm{FiO}_{2}$ ratio & $74(31-366)$ \\
\hline SOFA score & $7.69 \pm 2.69$ \\
\hline APACHE II score & $19.06 \pm 6.92$ \\
\hline \multicolumn{2}{|l|}{ Nutritional characteristics } \\
\hline mNUTRIC-Score & $4(0-8)$ \\
\hline Enteral nutrition, $n(\%)$ & $76(77.6 \%)$ \\
\hline No nutritional support, $n(\%)$ & $22(22.4 \%)$ \\
\hline \multicolumn{2}{|l|}{ Initial time of nutrition support } \\
\hline$\leq 48 \mathrm{~h}, n(\%)$ & $35(35.7 \%)$ \\
\hline$>48 \mathrm{~h}, n(\%)$ & $41(41.8 \%)$ \\
\hline \multicolumn{2}{|l|}{ Biochemicals } \\
\hline Glucose (mg/dL) & $162.50(45-533)$ \\
\hline Creatinine $(\mathrm{mg} / \mathrm{dL})$ & $1.25(0.30-20.23)$ \\
\hline $\mathrm{BUN}(\mathrm{mg} / \mathrm{dL})$ & $31.45(9-137)$ \\
\hline C-reactive protein $(\mathrm{mg} / \mathrm{dL})$ & $199.23 \pm 136.30$ \\
\hline Sodium (mmol/L) & $135.46 \pm 5.39$ \\
\hline Potassium $(\mathrm{mmol} / \mathrm{L})$ & $4.45(2.80-8.90)$ \\
\hline Magnesium (mg/dL) & $2.29 \pm 0.39$ \\
\hline Phosphorus (mg/dL) & $3.65(2-12.90)$ \\
\hline Lactate $(\mathrm{mmol} / \mathrm{L})$ & $2(0.60-7)$ \\
\hline \multicolumn{2}{|l|}{ Outcomes } \\
\hline Death at 28 -day, $n(\%)$ & $71(72.4 \%)$ \\
\hline
\end{tabular}

Abbreviations: APACHE II, Acute Physiology and Chronic Health Evaluation II; BUN, blood urea nitrogen; mNUTRIC-Score, modified Nutrition Risk in the Critically Ill-Score; $\mathrm{PaO}_{2} / \mathrm{FiO}_{2}$ ratio, partial pressure of arterial oxygen to fraction of inspired oxygen; SOFA, Sequential Organ Failure Assessment.

2.2. Statistical Analysis. All statistical analyzes were performed with SPSS version 21.0 (SPSS Inc., Chicago, IL, USA). A $p$ value $<0.05$ was considered statistically significant. Descriptive statistics were displayed as frequencies and percentages for categorical variables and means and standard deviation (SD) or median (min-max) for quantitative variables, depending on the distribution of variables (nonparametric or parametric) assessed by the Kolmogorov-Smirnov test. The chi-square test was used for categorical variables; continuous variables were compared and analyzed using the paired-samples $t$-test or the Mann-Whitney $U$ test. Logistic regression was used to analyze the association between clinical and nutritional factors with a risk of inpatient death. Then, we performed a multivariate Cox regression to establish the relationships between the mNUTRIC-Score and mortality in critically ill patients with COVID-19.

\section{Results}

3.1. Characteristics of the Study Population. A total of 98 patients with laboratory-confirmed COVID-19 were included in this study. Their demographic and clinical characteristics are listed in Table 1 . The mean age of the study cohort was $57.22 \pm 13.66$ years, and the majority of our patients were male (68.4\%). Hypertension (44.9\%), diabetes (35.7\%), coronary heart disease (17.3\%), and chronic kidney disease $(8.2 \%)$ were the four most common comorbidities. The median length of stay was 13 days (2-96 days), and the median length of mechanical ventilation duration was 7.5 days (1-40 days). Patients developed several complications, including acute kidney injury (63.3\%) and upper gastrointestinal bleeding (6.1\%); the proportion of patients who were treated with vasopressors was considerable (51\%). At the time of mechanical ventilation, patients had a mean SOFA score of $7.69 \pm 2.69$ and a mean APACHE II score of $19.06 \pm 6.92$. The 28 -day in-hospital mortality rate was $72.4 \%$, and those who died during the whole hospitalization were $77.6 \%$ (Table 1 ).

The median time to initiate feeding was 74 hours. Most patients received enteral nutrition (EN) (77.6\%), none received parenteral nutrition (PN), and $22.4 \%$ did not receive any nutritional support as a result of contraindications (Table 1).

3.2. Nutritional Risk and Outcomes. Patients were divided into high nutritional risk if they had a mNUTRIC-Score $\geq 5$ and low nutritional risk if they had a mNUTRIC-Score $<5$. Of the 98 patients available for the evaluation of the mNUTRIC-Score, $46.9 \%$ of the patients were classified as high nutritional risk and $53.1 \%$ of the patients as low nutritional risk. The median mNUTRIC-Score in the high-risk group was 6 (5-8). These groups of patients suffered greater comorbidities (evaluated with the Charlson comorbidity index) and greater incidence of acute kidney injury $(73.9 \%$ vs. $53.8 \%)$. There were no differences in the incidence of upper gastrointestinal bleeding or in terms of use of vasopressors between the groups. Significant differences concerning kidney function were observed between high- and low-risk groups: creatinine was $2.04 \mathrm{mg} / \mathrm{dL}$ vs. $0.96 \mathrm{mg} / \mathrm{dL}$ $(p=\leq 0.001)$ and BUN was 47.40 vs. $27.50(p=\leq 0.001)$, respectively. C-reactive protein was significantly higher in patients with mNUTRIC-Score $\geq 5 \quad(230.28 \pm 150.89$ vs. $171.77 \pm 116.6 ; p=0.033$ ). Mortality at 28 -days was $91.3 \%$ in the high-nutritional-risk group and $55.8 \%$ in the low-nutritional-risk group (Table 2).

Eighteen patients $(39.1 \%)$ in the high-nutritional-risk group received early feeding versus seventeen $(32.6 \%)$ in the low-nutritional-risk group $(p=0.193)$. The 28 -day mortality rate was not different between these 2 groups $(p=0.490)$. SOFA, APACHE II, and Charlson comorbidity index at admission were significantly higher in deaths than in survivors (Table 3). Elevated levels of blood urea nitrogen and creatinine were also observed in deaths, compared to survivors $(p \leq 0.001)$.

Logistic regression was performed for those variables, and we found age, Charlson comorbidity index, SOFA, APACHE II, BUN, mNUTRIC-Score, and acute kidney injury as 28-day mortality risk factors (Table 4). We divided patients into high- and low-risk mNUTRIC-Scores and 
TABLE 2: Characteristics and laboratory indices among patients with high and low nutritional risk.

\begin{tabular}{|c|c|c|c|}
\hline & $\begin{array}{l}\text { High-nutritional-risk group } \\
\text { (mNUTRIC-Score } \geq 5, n=46 \text { ) }\end{array}$ & $\begin{array}{l}\text { Low-nutritional-risk group } \\
\text { (mNUTRIC-Score }<5, n=52 \text { ) }\end{array}$ & $p$ value \\
\hline \multicolumn{4}{|l|}{ Clinical characteristics } \\
\hline Female, $n(\%)$ & $19(41.3 \%)$ & $12(23.1 \%)$ & 0.053 \\
\hline Male, $n(\%)$ & $27(58.7 \%)$ & $40(76.9 \%)$ & \\
\hline Age, mean & $61.91 \pm 12.39$ & $53.07 \pm 13.49$ & $\leq 0.001$ \\
\hline Comorbidities & $2(0-7)$ & $1(0-5)$ & $\leq 0.001$ \\
\hline Charlson comorbidity index & $4(2-9)$ & $2(0-5)$ & $\leq 0.001$ \\
\hline \multicolumn{4}{|l|}{ Biochemicals } \\
\hline Glucose $(\mathrm{mg} / \mathrm{dL})$ & $175(88-452)$ & $162(77-533)$ & 0.105 \\
\hline Creatinine $(\mathrm{mg} / \mathrm{dL})$ & $2.04(0.64-20.23)$ & $0.96(0.39-2.34)$ & $\leq 0.001$ \\
\hline $\mathrm{BUN}(\mathrm{mg} / \mathrm{dL})$ & $47.40(13-137)$ & $27.50(9-55)$ & $\leq 0.001$ \\
\hline Albumin $(\mathrm{g} / \mathrm{dL})$ & $2.47 \pm 0.49$ & $2.63 \pm 0.46$ & 0.115 \\
\hline C-reactive protein $(\mathrm{mg} / \mathrm{dL})$ & $230.28 \pm 150.89$ & $171.77 \pm 116.6$ & 0.033 \\
\hline \multicolumn{4}{|l|}{ Arterial blood gas } \\
\hline $\mathrm{pH}$ & $7.29 \pm 0.14$ & $7.34 \pm 0.14$ & 0.114 \\
\hline $\mathrm{PaCO}_{2}(\mathrm{mmHg})$ & $38(13-115)$ & $44(14-163)$ & 0.378 \\
\hline Bicarbonate $(\mathrm{mmol} / \mathrm{L})$ & $21.09 \pm 7.06$ & $24.19 \pm 4.93$ & 0.013 \\
\hline Lactate $(\mathrm{mmol} / \mathrm{L})$ & $2.10(0.70-7)$ & $2(0.60-4.9)$ & 0.889 \\
\hline $\mathrm{PaO}_{2} / \mathrm{FiO}_{2}(\mathrm{mmHg})$ & $69(33-366)$ & $84(31-360)$ & 0.020 \\
\hline \multicolumn{4}{|l|}{ Outcomes } \\
\hline Mechanical ventilation (days) & $10(3-33)$ & $10(3-40)$ & 0.162 \\
\hline Total mNUTRIC-Score, median (IQR), points & $6(5-8)$ & $2(0-4)$ & $\leq 0.001$ \\
\hline Hospital length of stay (days) & $10.5(2-34)$ & $15(2-96)$ & 0.004 \\
\hline Death at 28 th day, $n(\%)$ & $42(91.3 \%)$ & $29(55.8 \%)$ & $\leq 0.001$ \\
\hline Initial nutrition therapy (hours) & $48(12-168)$ & $76(12-240)$ & 0.208 \\
\hline \multicolumn{4}{|l|}{ Initial time of nutrition support } \\
\hline$\leq 48 \mathrm{~h}, n(\%)$ & $18(39.1 \%)$ & $17(32.7 \%)$ & 0.193 \\
\hline$>48 \mathrm{~h}, n(\%)$ & $15(32.6 \%)$ & $26(50 \%)$ & \\
\hline \multicolumn{4}{|l|}{ Complications, $n(\%)$} \\
\hline Acute kidney injury, $n(\%)$ & $34(73.9 \%)$ & $28(53.8 \%)$ & 0.004 \\
\hline Upper gastrointestinal bleeding, $n(\%)$ & $2(4.3 \%)$ & $4(7.7 \%)$ & 0.491 \\
\hline Vasopressors, $n(\%)$ & $27(58.7 \%)$ & $23(44.2 \%)$ & 0.153 \\
\hline
\end{tabular}

Abbreviations: BUN, blood urea nitrogen; mNUTRIC-Score, modified Nutrition Risk in the Critically Ill-Score; IQR, interquartile range; PaCO ${ }_{2}$, arterial partial carbon dioxide pressure; $\mathrm{PaO}_{2} / \mathrm{FiO}_{2}$ ratio, partial pressure of arterial oxygen to fraction of inspired oxygen.

found a strong association of $\geq 5$ points with the risk of death in the hospital $(\mathrm{OR}=8.328,95 \%$ CI: 2.604-26.630, $p=\leq 0.001)$. After adjusting for gender, age, and Charlson comorbidity index, a high-risk mNUTRIC-Score was an independent 28-day mortality risk factor $(\mathrm{OR}=4.206,95 \%$ CI: $1.147-15.425, p=0.030)$. The multivariate Cox regression analysis showed that after adjusting for age, Charlson comorbidity index, and acute kidney injury, patients with high-risk mNUTRIC-Score had a significantly increased full-length mortality risk during hospitalization $(\mathrm{OR}=1.991$, 95\% CI: 1.219-3.252, $p=0.006$ ) (Figure 2).

\section{Discussion}

This study demonstrates that the majority of critically ill patients with COVID-19 admitted to both the ICU and the internal medicine wards had a high nutritional risk. The significance of evaluating nutritional risk has been gathering clinical attention for its usefulness as a prognostic indicator in COVID-19 patients. Zhang et al. [15], in a retrospective study conducted in China, reported that a large proportion of critically ill COVID-19 patients had a high nutritional risk $(61 \%)$ as revealed by their mNUTRIC-Score. High- nutritional-risk scores were similarly prevalent (66\%) in an observational study conducted in the central region of Mexico [17]. In both studies, the mNUTRIC-Score was able to independently predict the risk of death at 28 days. Similar findings were observed in a larger study conducted by $\mathrm{Li}$ et al. [16], showing a significantly higher mortality in the high-nutritional-risk group (mNUTRIC-Score $\geq 5$ points). The results of the present study could not be fully compared with those of previous studies, as only $46.9 \%$ of our patients had a high nutritional risk. Nevertheless, a mNUTRIC-Score $\geq 5$ was consistently demonstrated to be associated with increased mortality risk in our study.

According to the mNUTRIC-Score, up to $40 \%$ of mechanically ventilated patients without COVID-19 are at nutritional risk [19-21], with higher scores directly proportional to the average length of stay in the ICU and mortality. Recent evidence indicates that COVID-19 patients are at even higher risk of malnutrition and mortality as demonstrated by mNUTRIC-Scores [15-17, 22], supporting the concept that SARS-CoV-2-mediated inflammatory state contributes to malnutrition and a poor prognosis. This could be explained as follows: First, muscle protein is consumed by the acute inflammatory response of SARS-CoV-2 infection. 
TABle 3: Comparison of each item among 28-day survivors and nonsurvivors.

\begin{tabular}{|c|c|c|c|}
\hline Clinical characteristics & Survivors, $n=27$ & Nonsurvivors, $n=71$ & $p$ value \\
\hline Female $n,(\%)$ & $10(37 \%)$ & $21(29.6 \%)$ & 0.478 \\
\hline Male $n,(\%)$ & $17(63 \%)$ & $50(70.4 \%)$ & \\
\hline Age, mean & $49.51 \pm 12.73$ & $60.15 \pm 12.91$ & $\leq 0.001$ \\
\hline Comorbidities & $1(0-4)$ & $1(0-7)$ & 0.101 \\
\hline Charlson comorbidity index & $2(0-4)$ & $3(0-9)$ & $\leq 0.001$ \\
\hline \multicolumn{4}{|l|}{ Severity of disease } \\
\hline SOFA score & $6.22 \pm 2.53$ & $8.25 \pm 2.56$ & $\leq 0.001$ \\
\hline APACHE II & $14.59 \pm 7.11$ & $20.76 \pm 6.09$ & $\leq 0.001$ \\
\hline \multicolumn{4}{|l|}{ Biochemical } \\
\hline Glucose (mg/dL) & $154(77-533)$ & $164(45-452)$ & 0.387 \\
\hline Creatinine $(\mathrm{mg} / \mathrm{dL})$ & $0.83(0.39-20.23)$ & $1.48(0.30-13.20)$ & $\leq 0.001$ \\
\hline BUN (mg/dL) & $22.60(10.50-137)$ & $34(9-108)$ & $\leq 0.001$ \\
\hline Albumin (g/dL) & $2.59 \pm 0.44$ & $2.54 \pm 0.50$ & 0.667 \\
\hline C-reactive protein $(\mathrm{mg} / \mathrm{dL})$ & $197.37 \pm 167.50$ & $199.95 \pm 123.78$ & 0.934 \\
\hline \multicolumn{4}{|l|}{ Arterial blood gas } \\
\hline $\mathrm{pH}$ & $7.35 \pm 0.14$ & $7.30 \pm 0.14$ & 0.156 \\
\hline $\mathrm{PaCO}_{2}(\mathrm{mmHg})$ & $38(14-163)$ & $45(13-114)$ & 0.694 \\
\hline Bicarbonate $(\mathrm{mmol} / \mathrm{L})$ & $23.37 \pm 7.13$ & $22.50 \pm 5.83$ & 0.538 \\
\hline Lactate $(\mathrm{mmol} / \mathrm{L})$ & $1.80(0.60-4.30)$ & $2.10(0.90-7)$ & 0.056 \\
\hline $\mathrm{PaO}_{2} / \mathrm{FiO}_{2}(\mathrm{mmHg})$ & $79(31-277)$ & $74(41-366)$ & 0.565 \\
\hline \multicolumn{4}{|l|}{ Outcomes } \\
\hline Mechanical ventilation (days) & $9(3-40)$ & $7(1-27)$ & 0.024 \\
\hline Total mNUTRIC-Score, median (IQR), points & $2(0-7)$ & $5(0-8)$ & $\leq 0.001$ \\
\hline mNutric-Score level, $n(\%)$ & $4(14.8 \%)$ & $42(59.2 \%)$ & $\leq 0.001$ \\
\hline Hospital length of stay (days) & $17(10-96)$ & $11(2-28)$ & $\leq 0.001$ \\
\hline Initial nutrition therapy (hours) & $76(12-240)$ & $72(24-240)$ & 0.713 \\
\hline \multicolumn{4}{|l|}{ Initial time of nutrition therapy } \\
\hline$\leq 48 \mathrm{~h}, n(\%)$ & $11(40.7 \%)$ & $24(33.8 \%)$ & 0.490 \\
\hline$>48 \mathrm{~h}, n(\%)$ & $16(59.3 \%)$ & $25(35.2 \%)$ & \\
\hline \multicolumn{4}{|l|}{ Complications, $n(\%)$} \\
\hline Acute kidney injury, $n(\%)$ & $10(37 \%)$ & $52(73.2 \%)$ & $\leq 0.001$ \\
\hline Upper gastrointestinal bleeding, $n$ (\%) & $2(7.4 \%)$ & $4(5.6 \%)$ & 0.744 \\
\hline Vasopressors, $n(\%)$ & $11(40.7 \%)$ & $39(54.9 \%)$ & 0.209 \\
\hline
\end{tabular}

Abbreviations: APACHE II, Acute Physiology and Chronic Health Evaluation II; BUN, blood urea nitrogen; mNUTRIC-Score, modified Nutrition Risk in the Critically Ill-Score; IQR, interquartile range; $\mathrm{PaCO}_{2}$, arterial partial carbon dioxide pressure; $\mathrm{PaO}_{2} / \mathrm{FiO}_{2}$ ratio, partial pressure of arterial oxygen to fraction of inspired oxygen; SOFA, Sequential Organ Failure Assessment.

TABLE 4: Logistic regression of significant variables for 28-day mortality.

\begin{tabular}{|c|c|c|c|c|}
\hline & OR & \multicolumn{2}{|c|}{ CI $95 \%$} & $p$ value \\
\hline Age & 1.062 & 1.024 & 1.102 & $\leq 0.001$ \\
\hline Charlson comorbidity index & 1.808 & 1.294 & 2.524 & $\leq 0.001$ \\
\hline SOFA score & 1.387 & 1.133 & 1.699 & 0.002 \\
\hline APACHE II & 1.179 & 1.079 & 1.290 & $\leq 0.001$ \\
\hline Creatinine $(\mathrm{mg} / \mathrm{dL})$ & 1.081 & 0.855 & 1.367 & 0.516 \\
\hline BUN $(\mathrm{mg} / \mathrm{dL})$ & 1.035 & 1.004 & 1.066 & 0.025 \\
\hline Total mNUTRIC-Score, median (IQR), points & 1.812 & 1.358 & 2.416 & $\leq 0.001$ \\
\hline mNUTRIC-Score $(\geq 5)$ & 8.328 & 2.604 & 26.630 & $\leq 0.001$ \\
\hline Acute kidney injury & 5.943 & 2.217 & 15.932 & $\leq 0.001$ \\
\hline
\end{tabular}

Cytokine storm of interferon- $\alpha$, interferon- $\gamma$, C-reactive protein, IL-6, IL-12, and tumor necrosis factor- $\alpha$ leads to metabolic stress and muscle catabolism (skeletal muscle is catabolized to provide the immune system with amino acids). Second, angiotensin-converting enzyme 2 is highly expressed in the gastrointestinal track [23]. Gastrointestinal symptoms such as diarrhea, abdominal pain, nausea, and vomiting are fairly common, accelerating the occurrence of malnutrition in patients with COVID-19. Poor appetite is related to anxiety (fear of their illness, isolation treatment, lack of normal social communication, etc.) which, in addition to anosmia and dysgeusia, could further aggravate malnutrition $[9,24]$.

The limited use of PN observed during the present study is in line with nutritional practices in critically ill adult ICU patients in Latin America, where less than one in ten patients received $\mathrm{PN}$ alone [25]. PN should be considered in the event of contraindication for $\mathrm{EN}$, if the objectives cannot be 


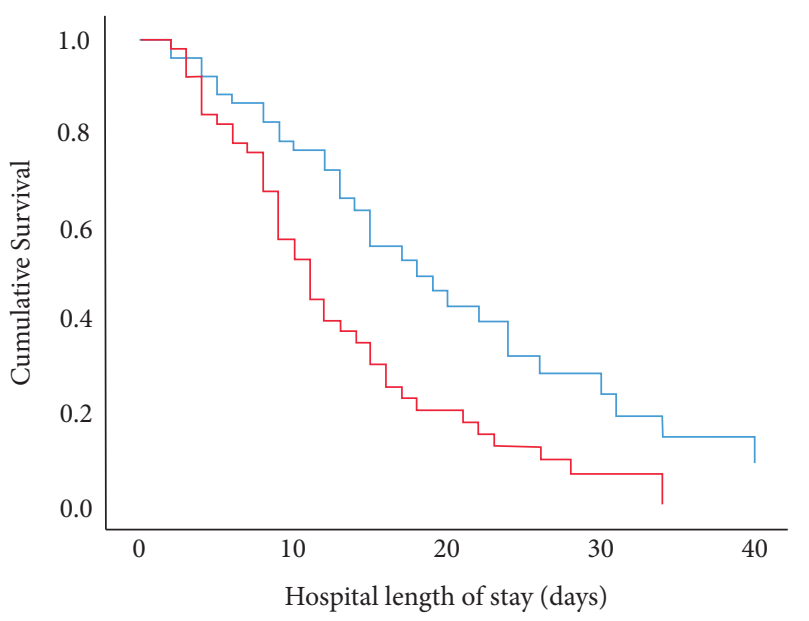

$\neg$ Low-risk
$\neg$ High-risk

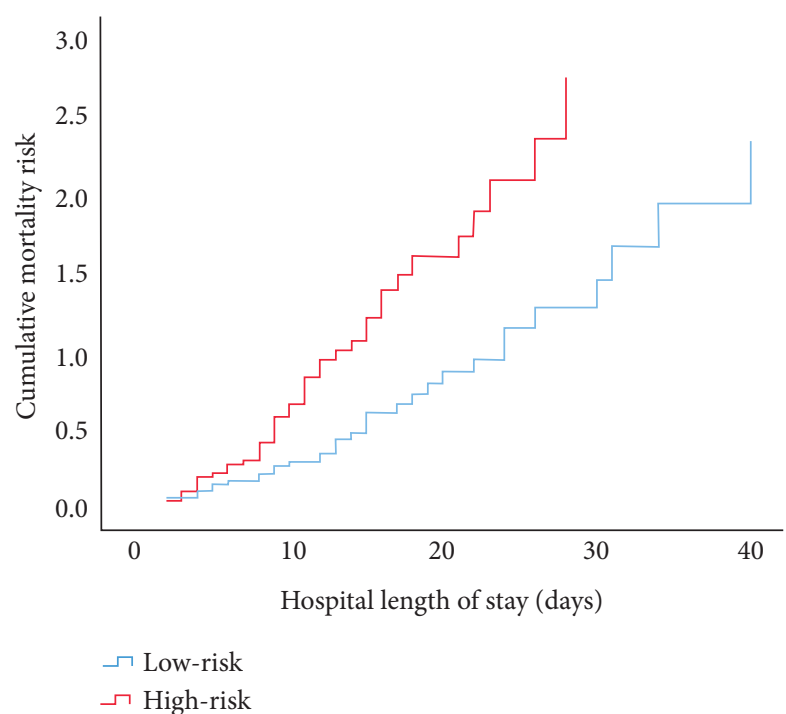

$\neg$ High-risk

Figure 2: Cumulative survival and mortality risk multivariate Cox regression analysis.

achieved with EN alone or in patients with gastrointestinal intolerance [18], a common occurrence in patients with COVID-19 admitted to the ICU [26].

Early EN, started within $48 \mathrm{~h}$ after ICU admission, preserves the intestinal mucosal barrier and has a beneficial effect on the reduction of enterogenic infections $[18,27]$. In our study, we observed a significant gap between the ESPEN recommendations and the actual feeding performance, as only $35.7 \%$ of the patients received EN within $48 \mathrm{~h}$. The initiation of EN may receive a lower priority compared to other interventions in critically ill patients with COVID-19 (airway-related procedures, imaging procedures, proning or supination process, physical therapy, nursing care, etc.). Inadequate training and knowledge regarding the principles of clinical nutrition could also impede the provision of nutrition support in a timely manner [28]. We observed no significant difference in mortality between patients who received early and delayed nutrition therapy in our study. This is in accordance with previous research articles and a systemic review from the Cochrane Collaboration [16, 29].

This study has several limitations related to its retrospective design. First, the study was conducted at a single hospital; therefore, the generalizability of the results may be challenged. Second, only 98 critically ill patients with COVID-19 were included in our study (statistical underpower cannot be ruled out). Third, there were no data in the electronic medical records that provide information on caloric and protein provision for the study population. Therefore, the association between nutritional adequacy, mNUTRIC-Scores, and mortality could not be explored.

\section{Conclusions}

Our data suggest that the mNUTRIC-Score, a fast and practical instrument, may be an appropriate tool for nutritional risk assessment and mortality risk for critically ill COVID-19 patients. These findings are important given the ongoing burden of the COVID-19 pandemic. Further prospective studies are needed to support our findings.

\section{Data Availability}

While the relevant data are included within the article, some data might not be shared as we are concerned about patients' privacy (the database includes names and hospital registry).

\section{Conflicts of Interest}

The authors declare no conflicts of interest.

\section{Authors' Contributions}

FGYE, ALOG, and KJAA, contributed to the conception and design of the research; FGYE, ALOG, DMHC, and LMRP contributed to the analysis and interpretation of the data; FGYE and CAAC wrote the manuscript; TGH and GVR reviewed the manuscript.

\section{Acknowledgments}

The authors thank all staff of Hospital Civil de Guadalajara Dr. Juan I. Menchaca involved in the COVID-19 patients care.

\section{References}

[1] I. Ibarra-Nava, K. G. Flores-Rodriguez, V. Ruiz-Herrera et al., "Ethnic disparities in COVID-19 mortality in Mexico: a crosssectional study based on national data," PLoS One, vol. 16, no. 3, Article ID e0239168, 2021.

[2] R. B. Larrazabal Jr., B. M. B. Perez, E. M. I. Masamayor, H. H. C. Chiu, and L. A. M. Palileo-Villanueva, "The prevalence of malnutrition and analysis of related factors among adult patients with the Coronavirus Disease 2019 (COVID 19) in a tertiary government hospital: the MalnutriCoV study," Clinical Nutrition ESPEN, vol. 42, pp. 98-104, 2021.

[3] Y. Yu, J. Ye, M. Chen et al., "Malnutrition prolongs the hospitalization of patients with COVID-19 infection: a clinical epidemiological analysis," The Journal of Nutrition, Health \& Aging, vol. 25, no. 3, pp. 369-373, 2021. 
[4] T. Çınar, M. İ. Hayıroğlu, V. Çiçek et al., "Is prognostic nutritional index a predictive marker for estimating all-cause in-hospital mortality in COVID-19 patients with cardiovascular risk factors?" Heart \& Lung, vol. 50, no. 2, pp. 307-312, 2021.

[5] X. Hu, H. Deng, Y. Wang, L. Chen, X. Gu, and X. Wang, "Predictive value of the prognostic nutritional index for the severity of coronavirus disease 2019," Nutrition, vol. 84, Article ID 111123, 2021.

[6] C. C. H. Lew, G. J. Y. Wong, K. P. Cheung, A. P. Chua, M. F. F. Chong, and M. Miller, "Association between malnutrition and 28-day mortality and intensive care length-ofstay in the critically ill: a prospective cohort study," Nutrients, vol. 10, 2017.

[7] L. Söderström, A. Rosenblad, E. Thors Adolfsson, and L. Bergkvist, "Malnutrition is associated with increased mortality in older adults regardless of the cause of death," British Journal of Nutrition, vol. 117, no. 4, pp. 532-540, 2017.

[8] H. J. Yeo, K. S. Byun, J. Han et al., "Prognostic significance of malnutrition for long-term mortality in community-acquired pneumonia: a propensity score matched analysis," The Korean Journal of Internal Medicine, vol. 34, no. 4, pp. 841-849, 2019.

[9] A. Rouget, F. Vardon-Bounes, P. Lorber et al., "Prevalence of malnutrition in coronavirus disease 19: the NUTRICOV study," British Journal of Nutrition, vol. 126, no. 9, pp. 1296-1303, 2020.

[10] R. Barazzoni, S. C. Bischoff, J. Breda et al., "ESPEN expert statements and practical guidance for nutritional management of individuals with SARS-CoV-2 infection," Clinical Nutrition, vol. 39, no. 6, pp. 1631-1638, 2020.

[11] D. K. Heyland, R. Dhaliwal, X. Jiang, and A. G. Day, "Identifying critically ill patients who benefit the most from nutrition therapy: the development and initial validation of a novel risk assessment tool," Critical Care, vol. 15, no. 6, p. R268, 2011.

[12] A. Rahman, R. M. Hasan, R. Agarwala, C. Martin, A. G. Day, and D. K. Heyland, "Identifying critically-ill patients who will benefit most from nutritional therapy: further validation of the "modified NUTRIC" nutritional risk assessment tool," Clinical Nutrition, vol. 35, no. 1, pp. 158-162, 2016.

[13] M. C. de Vries, W. Koekkoek, M. H. Opdam, D. van Blokland, and A. R. van Zanten, "Nutritional assessment of critically ill patients: validation of the modified NUTRIC score," European Journal of Clinical Nutrition, vol. 72, no. 3, pp. 428-435, 2018.

[14] A. Mukhopadhyay, J. Henry, V. Ong et al., "Association of modified NUTRIC score with 28-day mortality in critically ill patients," Clinical Nutrition, vol. 36, no. 4, pp. 1143-1148, 2017.

[15] P. Zhang, Z. He, G. Yu et al., "The modified NUTRIC score can be used for nutritional risk assessment as well as prognosis prediction in critically ill COVID-19 patients," Clinical Nutrition, vol. 40, no. 2, pp. 534-541, 2021.

[16] G. Li, C.-1. Zhou, Y.-m. Ba et al., "Nutritional risk and therapy for severe and critical COVID-19 patients: a multicenter retrospective observational study," Clinical Nutrition, vol. 40, no. 4, pp. 2154-2161, 2021.

[17] I. A. Osuna-Padilla, N. C. Rodríguez-Moguel, A. Aguilar-Vargas, and S. Rodríguez-Llamazares, "High nutritional risk using NUTRIC-Score is associated with worse outcomes in COVID-19 critically ill patients," Nutricion Hospitalaria, vol. 38, pp. 540544, 2021.
[18] P. Singer, A. R. Blaser, M. M. Berger et al., "ESPEN guideline on clinical nutrition in the intensive care unit," Clinical Nutrition, vol. 38, no. 1, pp. 48-79, 2019.

[19] H. M. Ata Ur-Rehman, W. Ishtiaq, M. Yousaf, S. Bano, A. M. Mujahid, and A. Akhtar, "Modified nutrition risk in critically ill (mNUTRIC) score to assess nutritional risk in mechanically ventilated patients: a prospective observational study from the Pakistani population," Cureus, vol. 10, Article ID e3786, 2018.

[20] M. K. Renuka, A. S. Arunkumar, and A. S. Arunkumar, "Use of nutrition risk in critically ill (NUTRIC) score to assess nutritional risk in mechanically ventilated patients: a prospective observational study," Indian Journal of Critical Care Medicine, vol. 21, no. 5, pp. 253-256, 2017.

[21] R. Mendes, S. Policarpo, P. Fortuna, M. Alves, D. Virella, and D. K. Heyland, "Nutritional risk assessment and cultural validation of the modified NUTRIC score in critically ill patients-A multicenter prospective cohort study," Journal of Critical Care, vol. 37, pp. 45-49, 2017.

[22] D. F. O. Silva, S. C. V. C. Lima, K. C. M. Sena-Evangelista, D. M. Marchioni, R. N. Cobucci, and F. B. d. Andrade, "Nutritional risk screening tools for older adults with COVID-19: a systematic review," Nutrients, vol. 12, no. 10, p. $2956,2020$.

[23] I. Hamming, W. Timens, M. Bulthuis, A. Lely, G. Navis, and H. van Goor, "Tissue distribution of ACE2 protein, the functional receptor for SARS coronavirus. A first step in understanding SARS pathogenesis," The Journal of Pathology, vol. 203, no. 2, pp. 631-637, 2004.

[24] F. Tang, J. Liang, H. Zhang, M. M. Kelifa, Q. He, and P. Wang, "COVID-19 related depression and anxiety among quarantined respondents," Psychology and Health, vol. 36, no. 2, pp. 164-178, 2021.

[25] K. P. Vallejo, C. M. Martínez, A. A. Matos Adames et al., "Current clinical nutrition practices in critically ill patients in Latin America: a multinational observational study," Critical Care, vol. 21, no. 1, p. 227, 2017.

[26] H. M. A. Kaafarani, M. El Moheb, J. O. Hwabejire et al., "Gastrointestinal complications in critically ill patients with COVID-19," Annals of Surgery, vol. 272, no. 2, pp. e61-e62, 2020.

[27] M. Delsoglio, C. Pichard, and P. Singer, "How to choose the best route of feeding during critical illness," Clinical Nutrition ESPEN, vol. 37, pp. 247-254, 2020.

[28] A. de Watteville, L. Genton, G. K. Barcelos, J. Pugin, C. Pichard, and C. P. Heidegger, "Easy-to-prescribe nutrition support in the intensive care in the era of COVID-19," Clinical Nutrition ESPEN, vol. 39, pp. 74-78, 2020.

[29] P. Fuentes Padilla, G. Martínez, R. W. Vernooij, G. Urrútia, M. Roqué i Figuls, and X. Bonfill Cosp, "Early enteral nutrition (within 48 hours) versus delayed enteral nutrition (after 48 hours) with or without supplemental parenteral nutrition in critically ill adults," Cochrane Database of Systematic Reviews, vol. 2019, Article ID CD012340, 2019. 